\title{
Occurrence and antimicrobial resistance of Salmonella spp. isolated from food other than meat in Poland
}

\author{
Łukasz Mąka', Elżbieta Maćkiw', Halina Ścieżyńska', Magdalena Popowska² \\ ${ }^{1}$ Laboratory of Food Microbiology, Department of Food Safety, National Institute of Public Health-National Institute of \\ Hygiene, Warsaw, Poland \\ 2 Department of Applied Microbiology, Institute of Microbiology, Faculty of Biology, University of Warsaw, Warsaw, Poland
}

Mąka $Ł$, Maćkiw E, Ścieżyńska H, Popowska M. Occurrence and antimicrobial resistance of Salmonella spp. isolated from food other than meat in Poland. Ann Agric Environ Med. 2015; 22(3): 403-408. doi: 10.5604/12321966.1167701

\section{Abstract}

Introduction and Objectives. Antimicrobial resistance of pathogenic bacteria can result in therapy failure, increased hospitalization, and increased risk of death. In Poland, Salmonella spp. is a major bacterial agent of food poisoning. The majority of studies on antimicrobial resistance in Salmonella spp. isolates from food have focused on meat products as the source of this pathogen. In comparison, this study examines the antimicrobial susceptibility of Salmonella spp. isolated from retail food products other than meat in Poland.

Materials and Methods. A collection of 122 Salmonella spp. isolates were isolated in Poland in 2008-2012 from foods other than meat: confectionery products, eggs, fruits, vegetables, spices and others. The resistance of these isolates to 19 antimicrobial agents was tested using the disc diffusion method.

Results. Salmonella Enteritidis was the most frequently identified serotype ( $84.4 \%$ of all tested isolates). In total, $42.6 \%$ of the Salmonella spp. isolates were resistant to antibiotics. The highest frequencies of resistance were observed in isolates from 2009 (60.0\%) and 2012 (59.5\%). Antibiotic resistance was most prevalent among Salmonella spp. isolated from egg-containing food samples (68.0\%). Resistance to nalidixic acid was most common and was observed in $35.2 \%$ of all tested isolates. The isolates were less frequently resistant to sulphonamides (6.6\%), ampicillin (4.9\%), amoxicillin/clavulanic acid (2.5\%) and to streptomycin, cefoxitin, gentamicin and tetracycline (1.6\%). Only one isolate showed resistance to chloramphenicol. Four isolates displayed multiresistance.

Conclusions. Although, the level of resistance and multiresistance of Salmonella spp. isolates from non-meat foods was lower than in those from meat products, the presence of these resistant bacteria poses a real threat to the health of consumers.

\section{Key words}

antimicrobial resistance, Salmonella spp., food, eggs

\section{INTRODUCTION}

Salmonella spp. are Gram-negative rod-shaped bacteria that commonly inhabit the intestinal tract of domestic and wild animals. More than 2,600 serovars comprise the Salmonella genus $[1,2]$. Transmission to humans is mostly associated with the ingestion of food containing bacteria as a result of cross-contamination, direct contact with animals, or a faecally-contaminated environment. Potential contamination problems may be enhanced by inappropriate food storage.

The clinical symptoms of salmonellosis include fever, abdominal pain, diarrhea and vomiting. The severity of the illness depends on the nature of the contaminated food, the infecting dose, and host factors, such as their existing gut flora and immunological condition. More severe salmonellosis occurs in immunocompromised people, the very young and the elderly [3].

Salmonellosis is the second most commonly reported gastrointestinal infection and an important cause of foodborne outbreaks in the European Union/European Economic Area (EU/EEA). Over 100,000 confirmed cases

Address for correspondence: Łukasz Mąka, Laboratory of Food Microbiology, Department of Food Safety, National Institute of Public Health-National Institute of Hygiene, Chocimska 24, 00-791 Warsaw, Poland

E-mail:Imaka@pzh.gov.pl

Received: 26 August 2013; accepted: 05 March 2014 were reported in 2010 and the Salmonella spp. serotypes most frequently identified were $S$. Enteritidis (45.0\%) and S. Typhimurium (22.0\%). In 2011, the number of confirmed cases decreased slightly to 95,548 and, as in previous years, S. Enteritidis and S. Typhimurium were the most frequently reported Salmonella serotypes (44.4\% and $24.9 \%$, respectively) $[2,4]$.

Antimicrobial resistance of pathogenic bacteria is a serious and growing problem. It can result in therapy failure, increased hospitalization and an increased risk of death. From an economic point of view, it greatly increases the costs of healthcare. Resistance to antibiotics is growing in the EU, especially among Gram-negative bacteria. Each year, about 25,000 patients die in the EU, Iceland and Norway from infections with antibiotic-resistant bacteria; two-thirds being due to Gram-negative bacteria. Infections caused by these resistant bacteria in the EU result in additional healthcare costs and lost productivity, amounting to at least EUR 1.5 billion each year $[5,6,7]$.

Antimicrobial resistance is a significant problem for food safety. Trade globalization and the international movement of food products mean that resistant bacteria may spread to consumers all around the world. In addition, horizontal gene transfer can enhance the dissemination of resistant bacteria, which increases the risk that new mechanism of resistance may be transferred via the food chain to the consumer. 
The majority of studies on antimicrobial resistance in Salmonella spp. isolates from food have focused on meat products as the source of this pathogen. This is understandable due to the use of antimicrobials in food-producing animals. In comparison, the problem of antibiotic resistance in bacteria isolated from foods other than meat has received little attention.

In addition to meat products, Salmonella spp. have also been isolated from eggs, sprouts, spices, fish, cheese, cake, ice cream and other foods. Besides meat, eggs and egg products (e.g. confectionery) are the main sources of Salmonella, although the incidence of contamination of these foodstuffs has decreased in recent years. Moreover, recent dietary trends have spread across Europe, including Poland. Increased awareness of a healthy diet has led to a reduction in meat consumption in favour of foods such as fresh fruits and vegetables. The availability and variety of spices is also greater than in the past. As dietary patterns change, it is necessary to consider the microbiological quality of these different foods [8].

The importance of foods other than meat as vehicles of Salmonella spp. is confirmed by notifications reported to the RASFF (Rapid Alert System for Food and Feed). RASFF is a tool for control authorities to exchange information about microbiological risks detected in food and animal feed, and the measures taken to respond to these threats [9]. Between 2008-2012, Salmonella spp. in products other than meat was responsible, on average, for around $50.0 \%$ of notifications in the hazard category 'pathogenic microorganisms' in food.

In the face of the increase in reported Salmonella spp. contamination of foods other than meat, it is important to examine the antibiotic resistance profiles of these isolates. The presented study examines the antimicrobial susceptibility of Salmonella spp. isolated from retail food products other than meat in Poland between 2008-2012.

\section{MATERIALS AND METHODS}

Isolates collection. A total of 122 Salmonella spp. isolates was collected by Sanitary and Epidemiological Stations across Poland in the course of their Official Control and Monitoring Programme (14 isolates in 2008, 30 in 2009, 29 in 2010, 12 in 2011 and 37 in 2012). The Salmonella spp. were isolated from food other than meat sampled according to PN-EN ISO 6579:2003/A1:2007 'Horizontal method for the detection of Salmonella spp.'

Antimicrobial susceptibility testing. The antimicrobial susceptibility of Salmonella spp. isolates was assessed by tests performed in 2011 and 2012. The antibiotic resistance profile of each isolate was determined using the disc diffusion method performed on Mueller-Hinton agar (OXOID, PO5007A), according to the methodology of the European Committee on Antimicrobial Susceptibility Testing (EUCAST) [10]. Discs containing the following antibiotics (OXOID) were used: aztreonam $(30 \mu \mathrm{g})$, amoxycillin/clavulanic acid $(20 / 10 \mu \mathrm{g})$, ampicillin $(10 \mu \mathrm{g})$, cefepime $(30 \mu \mathrm{g})$, cefotaxime $(5 \mu \mathrm{g})$, cefoxitin $(30 \mu \mathrm{g})$, ceftazidime $(10 \mu \mathrm{g})$, ceftriaxone $(30 \mu \mathrm{g})$, chloramphenicol $(30 \mu \mathrm{g})$, ciprofloxacin $(5 \mu \mathrm{g})$, ertapenem $(10 \mu \mathrm{g})$, gentamicin $(10 \mu \mathrm{g})$, imipenem $(10 \mu \mathrm{g})$, nalidixic acid $(30 \mu \mathrm{g})$, sulphonamides compound $(300 \mu \mathrm{g})$, streptomycin $(10 \mu \mathrm{g})$, tetracycline $(30 \mu \mathrm{g})$, trimethoprim $(5 \mu \mathrm{g})$, trimethoprim/sulphametoxazole $(1.25 / 23.75 \mu \mathrm{g})$.
Individual colonies were suspended in saline to a density of $0.5 \mathrm{acc}$. to the McFarland turbidity standard, measured using a densitometer (Biomerieux). Each cell suspension was spread over the entire surface of a plate by swabbing in 3 directions and the antibiotic discs were applied. The plates were then incubated at $35^{\circ} \mathrm{C}$ for $16-20 \mathrm{~h}$. The diameters of the zones of inhibition were measured and compared with EUCAST [10] or Clinical and Laboratory Standards Institute (CLSI) standards [11]. In cases where EUCAST breakpoints were absent (nalidixic acid, sulphonamides compounds, streptomycin and tetracycline), the results were interpreted according to the CLSI breakpoints. Quality control tests were performed using E. coli ATCC 25922.

Salmonella serotyping. Salmonella spp. isolates were serotyped by local Sanitary and Epidemiological Stations. Serotyping was performed by a slide agglutination test with specific $\mathrm{O}$ and $\mathrm{H}$ antisera (Immunolab, Biomed) and classified according to the White-Kauffmann-Le Minor scheme [1]. Where the serotype of an isolate was undefined, it was determined in the Department of Bacteriology at the National Institute of Public Health-National Institute of Hygiene (NIPH-NIH) in Warsaw, Poland.

Sample categorization. Considering the diversity of foods from which the isolates originated, they were divided into 4 categories:

1) confectionery (cakes with and without cream or custard, after heat treatment and without heat treatment, with additives, e.g. fruits, nuts, etc.);

2) eggs (egg content, eggshell);

3) fruits (fresh or dried), vegetables and spices;

4) other (foods not included in the other 3 categories, e.g. pasta, salad, fish, ice cream).

Statistical analysis. Statistical tests $\chi^{2}, \chi^{2}$ for trend in proportion, and Fisher's exact test (in the case of small number of isolates) were employed to determine the significance of the observed differences. For all analyses, significance level $p=0.05$ was assumed. OpenEpi 2.3.1 (http://www.openepi. com) software was used for calculations.

\section{RESULTS AND DISCUSSION}

Incidence of Salmonella spp. serotypes in various food categories. In total, 122 Salmonella spp. were isolated from various foods other than meat products (Tab. 1). Salmonella Enteritidis was by far the most frequently isolated serotype (84.4\%). Other serotypes were isolated more than once: S. Infantis (3.3\%), S. Newport (3.3\%), S. Poona (2.5\%) and S. Typhimurium (1.6\%).

The diversity of Salmonella spp. serotypes isolated from foods of the 4 defined categories is shown in Table 2. $S$. Enteritidis was the serotype most frequently isolated from confectionery ( $91.1 \%$ of isolates), eggs ( $84.0 \%)$ and other foods (90.0\%). Differences in the prevalence of $S$. Enteritidis in this food category were not statistically significant ( $p>0.05$ ). In samples of plant origin (fruits, vegetables and spices), $S$. Typhimurium and $S$. Newport were most frequently isolated (both $25.0 \%$ ). Only 8 isolates originated from food samples of this category, but 6 different serotypes were identified. 
Table 1. Incidence of Salmonella serotypes among isolates from nonmeat foodstuffs

\begin{tabular}{lcc}
\hline Serotype & $\%$ & $\mathrm{n}$ \\
\hline Salmonella Enteritidis & 84.4 & 103 \\
\hline Salmonella Infantis & 3.3 & 4 \\
\hline Salmonella Newport & 3.3 & 4 \\
\hline Salmonella Poona & 2.5 & 3 \\
\hline Salmonella Typhimurium & 1.6 & 2 \\
\hline Salmonella Bardo & 0.8 & 1 \\
\hline Salmonella Virchow & 0.8 & 1 \\
\hline Salmonella Singapore & 0.8 & 1 \\
\hline Salmonella Welteweden & 0.8 & 1 \\
\hline Salmonella Rissen & 0.8 & 1 \\
\hline monophasic strain* & 0.8 & $\mathbf{1 2 2}$ \\
\hline Total & & 1 \\
\hline
\end{tabular}

* monophasic Salmonella enterica subsp. enterica 1,4,12:d:-

Besides $S$. Enteritidis, which was detected in all 4 food categories, 2 other serotypes were also isolated from multiple categories: $S$. Infantis and $S$. Newport were identified in 3 categories. It is noteworthy that $S$. Typhimurium, a prevalent serotype in samples of plant origin (marjoram, cabbage), was not detected in any of the other food categories.

These results are similar to those obtained in some previous studies. Adesiyun et al. [12], and Suresh et al. [13] reported that $S$. Enteritidis was the serotype most frequently isolated from table eggs in Trinidad and eggshell in South India $(86.7 \%)$, respectively. Notably, these authors also detected 3 serovars, $S$. Cerro, $S$. Mbandaka and $S$. Molade, that were not identified in the present study.

Table 2. Diversity of Salmonella spp. serotypes in different categories of non-meat food

\begin{tabular}{|c|c|c|c|}
\hline Source & Serotype & $\%$ & $\mathrm{~N}$ \\
\hline \multirow[t]{6}{*}{ Confectionery } & Enteritidis & 91.1 & 72 \\
\hline & Poona & 3.8 & 3 \\
\hline & Infantis & 1.3 & 1 \\
\hline & Virchow & 1.3 & 1 \\
\hline & Newport & 1.3 & 1 \\
\hline & Bardo & 1.3 & 1 \\
\hline Total: & & & 79 \\
\hline \multirow[t]{4}{*}{ Eggs } & Enteritidis & 84.0 & 21 \\
\hline & Infantis & 8.0 & 2 \\
\hline & Newport & 4.0 & 1 \\
\hline & monophasic & 4.0 & 1 \\
\hline Total: & & & 25 \\
\hline \multirow{6}{*}{ Fruits, vegetables, spices } & Enteritidis & 12.5 & 1 \\
\hline & Typhimurium & 25.0 & 2 \\
\hline & Welteweden & 12.5 & 1 \\
\hline & Rissen & 12.5 & 1 \\
\hline & Newport & 25.0 & 2 \\
\hline & Singapore & 12.5 & 1 \\
\hline Total: & & & 8 \\
\hline \multirow[t]{2}{*}{ Other } & Enteritidis & 90.0 & 9 \\
\hline & Infantis & 10.0 & 1 \\
\hline Total: & & & 10 \\
\hline
\end{tabular}


Table 3. Antimicrobial resistance and intermediate susceptibility among different serotypes of Salmonella spp. isolated from non-meat foodstuffs ( $\mathrm{n}$ ) ATM - aztreonam; AMC - amoxycillin/clavulanic ac.; AMP - ampicillin; FEP - cefepime; CTX - cefotaxime; FOX - cefoxitin; CAZ - ceftazidime; CRO ceftriaxone; C - chloramphenicol; CIP - ciprofloxacin;

ETP - Ertapenem; CN - gentamicin; IPM - imipenem; NA - nalidixic Ac.; SUL - sulphonamides comp.; STR - streptomycin; TE - tetracycline; W trimethoprim; SXT - trimethoprim/sulphametoxazole

\begin{tabular}{|c|c|c|c|c|c|c|c|c|c|c|c|c|c|c|c|c|c|c|c|c|}
\hline \multirow{2}{*}{ Serotype } & \multirow{2}{*}{$\begin{array}{l}\text { No. of } \\
\text { isolates }\end{array}$} & \multicolumn{19}{|c|}{ Antimicrobial } \\
\hline & & ATM & AMC & AMP & FEP & CTX & FOX & CAZ & CRO & C & CIP & ETP & $\mathrm{CN}$ & IPM & NA & SUL & STR & TE & w & SXT \\
\hline Enteritidis & 103 & 0 & $11 ; 2 \mathrm{R}$ & $4 \mathrm{R}$ & 0 & 0 & $11 ; 2 R$ & 0 & 0 & 0 & 0 & 0 & $2 \mathrm{R}$ & 0 & $41 R$ & $61 ; 3 \mathrm{R}$ & $1 \mathrm{R}$ & $1 \mathrm{R}$ & 0 & 0 \\
\hline Infantis & 4 & 0 & 0 & 0 & 0 & 0 & 0 & 0 & 0 & 0 & 0 & 0 & 0 & 0 & $1 \mathrm{R}$ & $1 \mathrm{l} ; 2 \mathrm{R}$ & 11 & 0 & 0 & 0 \\
\hline Newport & 4 & 0 & 0 & 0 & 0 & 0 & 0 & 21 & 0 & 0 & 0 & 0 & 0 & 0 & 0 & $2 \mathrm{R}$ & 21 & 0 & 0 & 0 \\
\hline Poona & 3 & 0 & 0 & 0 & 0 & 0 & 0 & 0 & 0 & 0 & 0 & 0 & 11 & 0 & 0 & 0 & 11 & 0 & 0 & 0 \\
\hline Typhimurium & 2 & 0 & $1 \mathrm{R}$ & $1 \mathrm{R}$ & 0 & 0 & 0 & 0 & 0 & $1 \mathrm{R}$ & 0 & 0 & 0 & 0 & 0 & $1 \mathrm{R}$ & $1 \mathrm{l} ; 1 \mathrm{R}$ & $1 \mathrm{R}$ & 0 & 0 \\
\hline Bardo & 1 & 0 & 0 & $1 \mathrm{R}$ & 0 & 0 & 0 & 0 & 0 & 0 & 0 & 0 & 0 & 0 & 11 & 0 & 0 & 0 & 0 & 0 \\
\hline Virchow & 1 & 0 & 0 & 0 & 0 & 0 & 0 & 0 & 0 & 0 & 0 & 0 & 0 & 0 & $1 \mathrm{R}$ & 0 & 0 & 0 & 0 & 0 \\
\hline$\underline{\text { Singapore }}$ & 1 & 0 & 0 & 0 & 0 & 0 & 0 & 0 & 0 & 0 & 0 & 0 & 0 & 0 & 0 & 11 & 11 & 0 & 0 & 0 \\
\hline Welteweden & 1 & 0 & 0 & 0 & 0 & 0 & 0 & 0 & 0 & 0 & 0 & 0 & 0 & 0 & 0 & 0 & 0 & 0 & 0 & 0 \\
\hline Rissen & 1 & 0 & 0 & 0 & 0 & 0 & 0 & 0 & 0 & 0 & 0 & 0 & 0 & 0 & 0 & 0 & 0 & 0 & 0 & 0 \\
\hline monophasic & 1 & 0 & 0 & 0 & 0 & 0 & 0 & 0 & 0 & 0 & 0 & 0 & 0 & 0 & 0 & 0 & 11 & 0 & 0 & 0 \\
\hline Total & 122 & 0 & $11 ; 3 R$ & $6 \mathrm{R}$ & 0 & 0 & $11 ; 2 R$ & 21 & 0 & $1 \mathrm{R}$ & 0 & 0 & $11 ; 2 R$ & 0 & $11 ; 43 R$ & $81 ; 8 \mathrm{R}$ & $71 ; 2 R$ & $2 \mathrm{R}$ & 0 & 0 \\
\hline
\end{tabular}

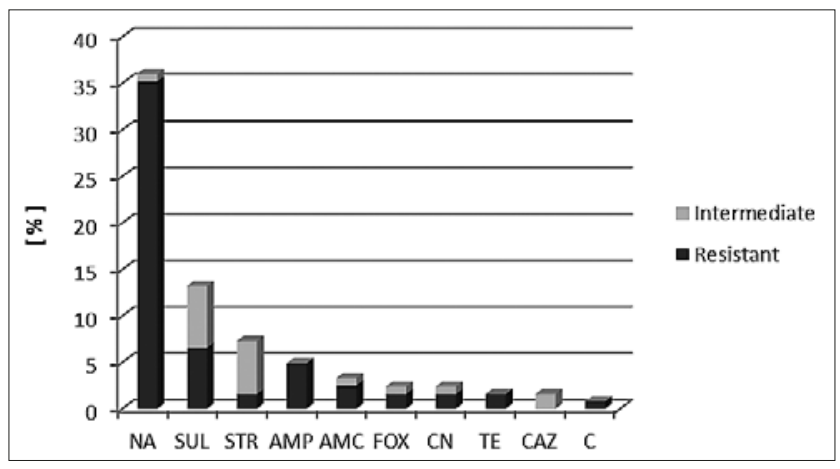

Figure 1. Antimicrobial resistant Salmonella spp. isolates

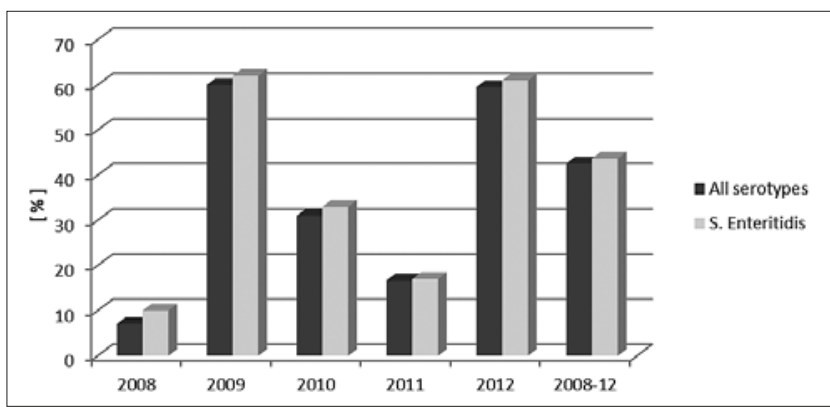

Figure 2. Annual percentages of resistant Salmonella spp. of all serotypes compared to $S$. Enteritidis

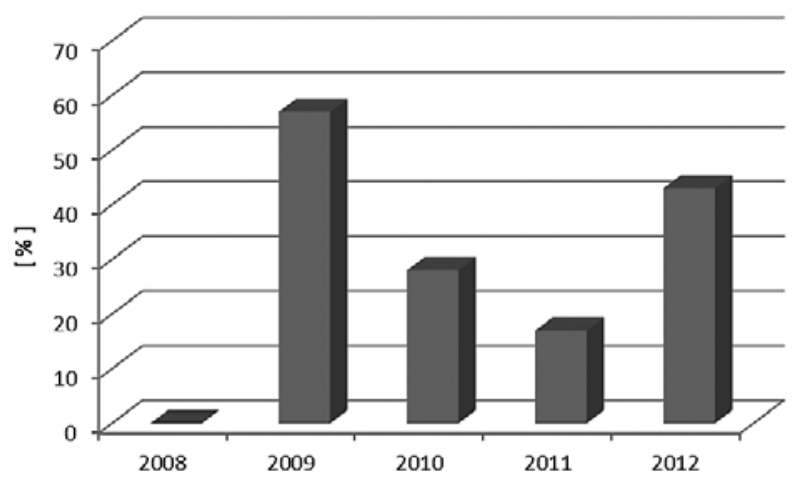

Figure 3. Annual percentages of Salmonella spp. resistant to nalidixic acid
If the source of the isolates is considered, $68.0 \%$ of them obtained from egg samples during the study period were resistant to antibiotics (Fig. 4). This is considerably higher than the proportion of resistant Salmonella spp. isolated from table eggs in Trinidad (22.9\%) by Adesiyun et al. [12]. Among all isolates examined in their study, $14.9 \%$ were resistant to streptomycin, $6.8 \%$ to nalidixic acid, $2.7 \%$ to kanamycin and $1.4 \%$ to gentamycin [12]. Suresh et al. [13] reported that among 39 Salmonella spp. isolated from eggs in south India, all were resistant to ampicillin, neomycin, polymyxin-B and tetracycline.

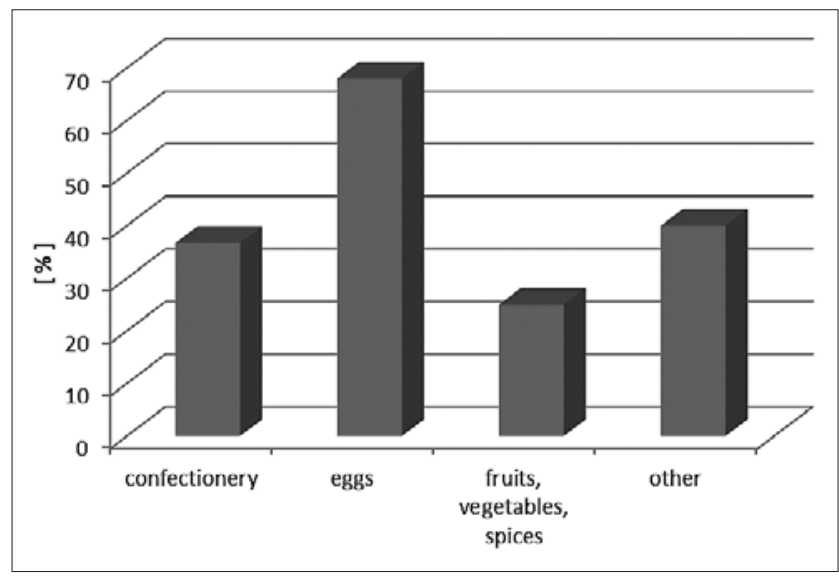

Figure 4. Antimicrobial resistance among Salmonella spp. isolated from various sources

Resistance among Salmonella spp. isolates obtained from 'confectionery' and 'other sources' were similar, amounting to $36.7 \%$ and $40.0 \%$, respectively. Among isolates from 'fruits, vegetables, spices', $25.0 \%$ showed antibiotic resistance (results are on the border of statistical significance; $\mathrm{p}=0.07$ ).

In the study of Van Doren et al. [16] investigating antimicrobial resistance of Salmonella spp. in spices, $6.8 \%$ of isolates exhibited antimicrobial resistance, of which more than half were resistant to nalidixic acid. Resistance to the following antibiotics was also frequently detected among the isolates: sulfisoxazole (10 resistance /14 resistant isolates), 
tetracycline (9/14), chloramphenicol (6/14), streptomycin (5/14), kanamycin (4/14) and ampicillin (3/14).

Of Salmonella spp. contaminating food imported into the United States, $11.0 \%$ were found to be resistant to at least one antimicrobial agent. Resistance to nalidixic acid was observed in only $3.0 \%$ of isolates [19]. The most frequently detected resistance was to tetracycline $(9.0 \%)$, sulfamethoxazole $(5.0 \%)$ and streptomycin (4.0\%).

The antibiotic resistance profile of the isolates tested in the presented study is quite different from that of isolated from retail meats. Among the isolates from meat products from retail in Poland, during the same period of time (20082012 ), resistance to nalidixic acid was prevalent (52.8\% of all tested isolates), but tetracycline (32.1\%), ampicillin (28.3\%), streptomycin (28.3\%) and sulphonamides (26.4\%) resistance was also common. Both the frequency of resistance to this antimicrobials and the total level of resistance were lower among isolates from food other than meat (42.6\% compared to $68.9 \%$ of Salmonella spp. isolated from meat products) [20]. Among Salmonella spp. isolated from retail pork and chicken meat in North Vietnam, resistance to at least one antimicrobial agent was found in $78.4 \%$ [21]. The highest frequency of resistance was to tetracycline (58.5\%), followed by sulphonamides (58.1\%), streptomycin (47.3\%), ampicillin (39.8\%), chloramphenicol (37.3\%), trimethoprim (34.0\%) and nalidixic acid $(27.8 \%)$. A low incidence of resistance to amoxicillin-clavulanic acid (2.1\%), norfloxacin (1.2\%) and ciprofloxacin (5.0\%) was found in such isolates [21]. In China, resistance to sulfamethoxazole, sulfamethoxazole/ trimethoprim and nalidixic acid was very common in Salmonella spp. isolates from meats [22]. Nalidixic acid resistance was especially prevalent in isolates from chicken meat.

The rate of $57.7 \%$ antibiotic resistance detected in Salmonella spp. isolated from beef, pork and poultry in Austria is comparable with that found in the presented study [23]. In comparison, among Salmonella spp. isolated from chicken carcasses in Italy, $86.1 \%$ were resistant to tetracycline, $80.5 \%$ were resistant to sulfamethoxazole, and $33.3 \%$ were resistant to ampicillin [24].

Antimicrobial resistance of Salmonella Enteritidis isolates. Of the 122 Salmonella spp. isolates tested in the current study, 103 were $S$. Enteritidis. The occurrence of antibiotic resistance among the isolates of this serotype was analyzed. Because of the prevalence of $S$. Enteritidis, the results are very similar to those obtained when all isolates were considered (Fig. 2). The data do not exhibit any systematic trend (no increase nor decrease). The highest percentage of resistant isolates was observed in 2009 and $2012(62.0 \%$ and $61.0 \%$, respectively). In 2008, 9.7\% showed resistance. Overall, $43.7 \%$ of the isolated S. Enteritidis strains were antibiotic resistant, while $39.8 \%$ were resistant to nalidixic acid. Among all resistant $S$. Enteritidis isolates, 91.1\% showed resistance to this quinolone. Lower frequencies of resistance to other antimicrobials was detected among the $S$. Enteritidis isolates: $8.9 \%$ were resistant to ampicillin, $6.7 \%$ to sulphonamides, $4.4 \%$ to amoxycillin/clavulanic acid, cefoxitin and gentamicin, and $2.2 \%$ to streptomycin and tetracycline.

The study of Campioni et al. [25] included isolates from sources different from those examined in the current study, but resistance to nalidixic acid was also the most common among resistant Salmonella Enteritidis isolates (28.1\%), and only $0.8 \%$ were resistant to trimethoprim-sulfamethoxazole and streptomycin. However, these rates of resistance are lower than those observed in the present study.

Multiresistance. The numbers of isolates exhibiting multiresistance (resistance to 3 or more antimicrobial agents) are shown in Table 4 . The vast majority of resistant isolates $(82.7 \%)$ displayed resistance to one antimicrobial, while only 4 were resistant to 3 or more antimicrobials (3.3\% of all tested isolates, $7.7 \%$ among resistant isolates); 2 of them were $S$. Enteritidis isolated from cakes in 2010 (one resistant to nalidixic acid, sulphonamides, streptomycin and tetracycline and one resistant to amoxicillin/clavulanic acid, ampicillin, cefoxitin, nalidixic acid), one $S$. Enteritidis isolated from cake in 2012 (resistant to amoxicillin/clavulanic acid, ampicillin and cefoxitin) and one S. Typhimurium isolated in 2012 from cabbage salad (resistant to amoxicillin/clavulanic acid, ampicillin, chloramphenicol, sulphonamides, streptomycin and tetracycline).

According to Adesiyun et al. [12], the incidence of multiresistance in $S$. Enteritidis isolated from eggs was $1.4 \%$. Zhao et al. [19], reported that $3.4 \%$ of Salmonella spp. isolates contaminating food imported to the United States were resistant to more than 3 antimicrobials. Higher percentages (57.0\%) of multiresistant Salmonella spp. isolates have been observed in other studies [16].

Table 4. Multiresistance of Salmonella spp. isolates

\begin{tabular}{lcccccc}
\hline Serotype & \multicolumn{5}{c}{ No. of antimicrobials } \\
\cline { 2 - 6 } & 1 & 2 & 3 & 4 & 5 & 6 \\
\hline Salmonella Enteritidis & 38 & 4 & 1 & 2 & & \\
\hline Salmonella Infantis & 1 & 1 & & & \\
\hline Salmonella Newport & 2 & & & & \\
\hline Salmonella Poona & & & & & \\
\hline Salmonella Typhimurium & & & & & \\
\hline Salmonella Bardo & 1 & & & & \\
\hline Salmonella Virchow & 1 & & & & \\
\hline Salmonella Singapore & & & & & \\
\hline Salmonella Welteweden & & & & & \\
\hline Salmonella Rissen & & & & & \\
\hline monophasic strain* & & & $\mathbf{5}$ & & & \\
\hline Total: & & & & & \\
\hline
\end{tabular}

\section{CONCLUSIONS}

The main serotype of Salmonella spp. isolated from foods other than meat in Poland between 2008-2012 was $S$. Enteritidis.

Of the antibiotic resistant isolates identified, the great majority showed resistance to only one antimicrobial agent. Among the isolates, resistance to nalidixic acid was most prevalent, while resistance to sulphonamides and tetracycline was observed in a small percentage.

The presented results reveal that there are differences between the antimicrobial resistance profiles of Salmonella spp. isolated from meat products and those from other foods. The percentage of resistant and multiresistant isolates appears to be lower than among isolates isolated from meat products. 
However, this does not change the real threat to the health of consumers.

\section{Acknowledgments}

This work was supported by a Grant from the National Centre of Science awarded under decision DEC-2011/01/N/ NZ9/00197. The authors wish to thank Dr. Jolanta Szych, Monika Wasiak and the Department of Bacteriology of the National Institute of Public Health - National Institute of Hygiene in Warsaw, Poland, for serotyping the Salmonella spp. isolates.

\section{REFERENCES}

1. Grimont PAD, Weill F-X. Antigenic formulae of the Salmonella serovars. $9^{\text {th }}$ ed. WHO Collaborating Centre for Reference and Research on Salmonella, Institut Pasteur, 2007.

2. EFSA and ECDC. The European Union Summary Report on Trends and Sources of Zoonoses, Zoonotic Agents and Food-borne Outbreaks in 2011. EFSA Journal. 2013; 11(4): 3129.

3. Dougan G, John V, Palmer S, Mastroeni P. Immunity to salmonellosis. Immunol Rev. 2011; 240: 196-210.

4. European Centre for Disease Prevention and Control (ECDC). Annual epidemiological report. Reporting on 2010 surveillance data and 2011 epidemic intelligence data. ECDC, 2012 http://www.ecdc.europa.eu/ en/publications/Publications/Annual-Epidemiological-Report-2012. pdf (access: 2013.09.01)

5. ECDC/EMEA. Joint Technical Report “The bacterial challange: time to react. A call to narrow the gap between multidrug-resistant bacteria in the EU and the development of antibacterial agents. Stockholm, 2009.

6. Maragakis LL, Perencevich EN, Cosgrove SE. Clinical and economic burden of antimicrobial resistance. Expert Rev Anti-Infe. 2008; 6: 751-763.

7. Slama TG. Gram-negative antibiotic resistance: there is a price to pay. Crit Care. 2008; 12(Suppl 4): S4.

8. European Commission, Special Eurobarometer. Healt and Food, 2006.

9. Rapid Alert System for Food and Feed http://ec.europa.eu/food/food/ rapidalert/index_en.htm (access: 2013.09.01).

10. EUCAST (the European Committee on Antimicrobial Susceptibility Testing). Antimicrobial susceptibility testing. EUCAST disk diffusion method, Version 2.1, 2012.

11. CLSI. Clinical and Laboratory Standards Institute. Performance Standards for Antimicrobial Susceptibility Testing. Wayne, PA.TwentySecond Information. Supplement M100-S22 2012; 32(3).

12. Adesiyun A, Offiah N, Seepersadsingh N, Rodrigo S, Lashley V, Musai L. Antimicrobial resistance of Salmonella spp. and Escherichia coli isolated from table eggs. Food Control. 2007; 18(4): 306-311.
13. Suresh T, Hatha AAM, Sreenivasan D, Sangeetha N, Lashmanaperumalsamy P. Prevalence and antimicrobial resistance of Salmonella enteritidis and other salmonellas in the eggs and egg-storing trays from retail markets of Coimbatore, South India. Food microbial. 2006; 23(3): 294-299.

14. Karczmarczyk M, Martins M, McCusker M, Mattar S, Amaral L, Leonard $\mathrm{N}$, et al. Characterization of antimicrobial resistance in Salmonella enterica food and animal isolates from Colombia: identification of a qnrB19-mediated quinolone resistance marker in two novel serovars. FEMS microbiol lett. 2010; 313(1): 10-19.

15. Patrick ME, Adcock PM, Gomez TM, Altekruse SF, Holland BH, Tauxe RV, et al. Salmonella Enteritidis infections, United States, 1985-1999. Emerg Infect Dis. 2004; 10(1): 1-7.

16. Van Doren JM, Kleinmeier D, Hammack TS, Westerman A. Prevalence, serotype diversity, and antimicrobial resistance of Salmonella in imported shipments of spice offered for entry to the United States, FY2007-FY2009. Food Microbiol. 2013; 34(2): 239-251.

17. Food Safety Authority of Ireland. 3rd Trimester National Microbiological Survey 2004 (04NS3) of the European Commission Coordinated Programme for the Official Control of Foodstuffs for 2004: Bacteriological and Toxicological Safety of Dried Herbs and Spices. 2005 http://www.fsai.ie/uploadedFiles/Monitoring_and_ Enforcement/Monitoring/Surveillance/safety_herbs_spices_2004. pdf (access: 2013.09.01).

18. Eaves DJ, Randall L, Gray DT, Buckley A, Woodward MJ, White AP, et al. Prevalance of Mutations within the Quinolone ResistanceDetermining Region of gyrA, gyrB, parC and parE and Association with Antibiotic Resistance in Quinolone-Resistant Salmonella enterica. Antimicrob Agents Ch. 2004; 48(10): 4012-4015.

19. Zhao S, McDermott PF, Friedman S, Qaiyumi S, Abbott J, Kiessling C, et al. Characterization of antimicrobial-resistant Salmonella isolated from imported food. J Food Protect. 2006; 69(3): 500-507.

20. Mąka Ł, Maćkiw E, Ścieżyńska H, Pawłowska K, Popowska M. Antimicrobial susceptibility of Salmonella strains isolated from retail meat products in Poland between 2008 and 2012. Food Control 2014; 36: 199-204. doi: 10.1016/j.foodcont.

21. Thai TH, Hirai T, Lan NT, Yamaguchi R. Antibiotic resistance profiles of Salmonella serovars isolated from retail pork and chicken meat in North Vietnam. Int J Food Microbiol. 2012; 156(2): 147-151.

22. Yan H, Li L, Alam MJ, Shinoda S, Miyoshi S-I, Shi L. Prevalence and antimicrobial resistance of Salmonella in retail foods in northern China. Int J Food Microbiol. 2010; 143(3): 230-234.

23. Mayrhofer S, Paulsen P, Smulders FJM, Hilbert F. Antimicrobial resistance profile of five major food-borne pathogens isolated from beef, pork and poultry. Int J Food Microbiol. 2004; 97: 23-29.

24. Bacci C, Boni E, Alpigiani I, Lanzoni E, Bonardi S, Brindani F. Phenotypic and genotypic features of antibiotic resistance in Salmonella enterica isolated from chicken meat and chicken and quail carcasses. Int J Food Microbiol. 2012; 160: 16-23.

25. Campioni F, Moratto Bergamini AM, Falcão JP. Genetic diversity, virulence genes and antimicrobial resistance of Salmonella Enteritidis isolated from food and humans over a 24-year period in Brazil. Food Microbiol. 2012; 32(2): 254-264. 